\title{
Poor Agreement between Predictive Equations of Energy Expenditure and Measured Energy Expenditure in Critically III Acute Kidney Injury Patients
}

\author{
Cassiana R. de Góes $^{b}$ Marina N. Berbel-Bufarah ${ }^{b} \quad$ Ana Claudia S. Sanches ${ }^{b}$ \\ Patrícia S. Xavier ${ }^{b}$ André L. Balbi ${ }^{a}$ Daniela Ponce ${ }^{a}$ \\ ${ }^{\mathrm{a}}$ Internal Medicine Department and ${ }^{\mathrm{b}}$ Nutritionists, Acute Kidney Injury Group, UNESP - Universidade Estadual \\ Paulista, Faculdade de Medicina de Botucatu, Botucatu, Brazil
}

\section{Key Words}

Acute kidney injury · Energy expenditure $\cdot$ Indirect calorimetry

\begin{abstract}
Background: There are multiple equations for predicting resting energy expenditure (REE), but how accurate they are in severe acute kidney injury (AKI) patients is not clear. Our aim was to determine if predictive equations for estimated REE accurately reflect the requirements of AKI patients. Methods: We included in this prospective and observational study AKI patients AKIN-3 assessed by indirect calorimetry (IC). Bland-Altman, intraclass correlation coefficient and precision (percentagem of predicted values within $10 \%$ of measured values) were performed to compare REE by equations with REE measured by IC. Results: IC was applied in 125 AKI patients. The mean age was $62.5 \pm 16.6$ and $65.6 \%$ were male. Mean REE measured was 2,029.11 $\pm 760.4 \mathrm{kcal} /$ day. There were low precision, and poor agreement between measured and predicted REE by the Harris-Benedict (HB), Mifflin, Ireton-Jones, Penn state, American College of Chest Physicians, and Faisy equations. HB without using injury factor was the least precise (18\% of precision). Modified Penn state equation had the best precision, although the precision rate was only $41 \%$. For all equations, the limits of agree-
\end{abstract}

\section{KARGER}

(c) 2016 S. Karger AG, Basel

0250-6807/16/0684-0276\$39.50/0

E-Mail karger@karger.com

www.karger.com/anm ment range were large leading to the potential under or overfeeding of individual patients. Conclusion: None of these equations accurately estimated measured REE in severe AKI patients and most of them underestimated energy needs.

(c) 2016 S. Karger AG, Basel

\section{Introduction}

Acute kidney injury (AKI) occurs in approximately $3-15 \%$ of hospitalized patients and can affect $30-50 \%$ of patients admitted to intensive care units (ICU). It is associated with extremely high mortality rates, ranging from 20 to $50 \%$ [1].

Previous observational studies reported that malnourished and hospitalized AKI patients have higher rates of morbidity and mortality than well-nourished patients [2, 3 ] and an association between cumulative caloric deficits and poor outcome in ICU patients $[4,5]$. Accurate determination of energy needs is obviously important in critically ill patients because both over and underfeeding may be associated with complications and undesired consequences [6].

Underfeeding disturbs the regeneration of respiratory epithelium and causes respiratory muscle dysfunction 
which may prolong ventilator dependence. Even when subclinically present, it is responsible for reduced superficial and deep wound healing. Also, the failure to provide $>25 \%$ of recommended calories significantly increases the risk of bloodstream infection [7, 8]. Similarly, the deleterious effects associated with significant overfeeding, such as poor glycemic control, altered neuroendocrine responses, increased risk of infectious complications, delayed liberation from mechanical ventilation, or even increased mortality rate, have been described [9-11].

In AKI patients, hypermetabolism and hypercatabolism may be present since it is a part of a more complex illness such as sepsis, multiple organ failure, shock, trauma, or high risk surgery [12]. Determining an appropriate method for predicting energy needs has been an area of research for many years and is essential in the treatment of these patients.

Determining energy requirements in the critically ill patient via indirect calorimetry (IC) has long been considered the gold standard [12]. Limitations for using IC include time constraints, equipment availability, staffing, and cost. Therefore, many predictive equations exist for predicting resting energy expenditure (REE), but the accuracy of these equations for estimating caloric requirements for critically ill patients is not clear $[6,13-16]$. The equations include Harris-Benedict (HB) [17], Mifflin [18, 19], Ireton-Jones [20, 21], Penn state [22, 23], Faisy [13] and American College of Chest Physicians (ACCP) guidelines [24], among others. Most of the predictive equations were typically derived from studies of healthy, non-hospitalized individuals, while only a few have been validated in mechanically ventilated patients [5-13] and one has been validated for chronic dialysis patients [25], but to our knowledge, none of these equations has been validated for AKI patients.

Due to the practical limitations of routine IC as well as the absence of data to support existing predictive equations in AKI patients, we set out to determine if standard predictive equations for energy expenditure accurately reflect the energy requirements of critically ill, mechanically ventilated AKI patients.

\section{Methods}

A prospective and observational study was conducted from October 2012 to October 2014 in a university teaching hospital. This study was approved by the ethics committee. Since the participants were not able to give informed consent, the legal caregiver provided their written informed consent before entry into study.

Agreement of Predictive and Measured REE in Severe AKI
Inclusion criteria were AKI patients AKIN-3, defined as serum creatinine increased $>300 \%$ of basal or urine output $<0.3 \mathrm{ml} / \mathrm{kg} / \mathrm{h}$, in $24 \mathrm{~h}$ or anuria in $12 \mathrm{~h}$; or patients requiring dialysis, independently of the serum creatinine or urine output [26] mechanically ventilated with measured IC. Patients were not on dialysis at the time of measurement REE. Those who had dialysis indication had not yet begun the procedure. Exclusion criteria were fraction of inspired oxygen $\left(\mathrm{FiO}_{2}\right)>0.60$; positive end-expiratory pressure $>10 \mathrm{~cm} \mathrm{H} \mathrm{H}_{2} \mathrm{O}$; maximum airway pressure $>60 \mathrm{~cm} \mathrm{H} \mathrm{H}_{2} \mathrm{O}$; agitation; neuromuscular blockers; air leak in the ventilator circuit, around the endotracheal tube cuff, or from a bronchopleural fistula.

IC Was Performed Using Quark RMR (Cosmed, Rome, Italy)

The Quark RMR is designed to accurately and instantaneously measure energy requirements of either spontaneously breathing or mechanically assisted patients. In our study, the metabolic monitor has been utilized connected with a ventilator, with a turbine flow-meter placed at the ventilator outlet and the gas sampling port is inserted in line with the breathing circuit: by this way, it becomes possible to sample both inspiratory and expiratory gases. The calorimeter had a paramagnetic oxygen sensor for measuring oxygen concentrations and analyzers based on infrared absorption for carbon dioxide measurements. Gases are sampled at fixed flowrate from the ventilator circuit and drawn into the device. After that, calculate $\mathrm{VO}_{2}$ and $\mathrm{VCO}_{2}$. For measuring the $\mathrm{EE}$, use the Weir equation [27]:

$$
\mathrm{REE}=\left(\left(3.941 \times \mathrm{VO}_{2}\right)+\left(1.11 \times \mathrm{VCO}_{2}\right)\right) \times 1.44 .
$$

IC was calibrated before each use. The protocol required that patients be inactive and undisturbed for $30 \mathrm{~min}$ prior to testing and for 30-minute duration of the data collection. It is recommended that patients achieve steady state during testing. Steady state was defined as a variability of $<10 \%$ in the measurements of oxygen consumption and carbon dioxide production, and $<5 \%$ in the respiratory quotient from minute to minute.

Parenteral and/or enteral nutrition were continued during the data collection period. Patient height was a measured value, taken at the admission, when possible, or the value documented in the medical record. Weight was measured using calibrated hospital scales, at the admission, in most patients. If the patient had edema in the moment of measure, according to the medical evaluation, the general weight maintained by the patient was obtained from family members/caregivers and used as actual weight. Body mass index (BMI, $\mathrm{kg} / \mathrm{m}^{2}$ ) was calculated. For all equations, the patient's admission body weight was used for 'actual body weight'. The predictive equations used and details of their use are summarized in table 1.

Results were expressed as numbers and percentages, means \pm SDs, or medians and ranges (for data with no normal distribution). Measured and calculated REE were compared by using correlation coefficients, and Bland-Altman analysis. The intraclass correlation coefficient (ICC) was used to test the inter method reproducibility of the REE measured by the IC and the prediction equations. Coefficient values $>0.4$ were considered indicative of poor reproducibility, values between 0.4 and 0.75 indicative of moderate reproducibility and values $<0.75$ indicative of good reproducibility [28].

Bland-Altman analysis is a process used to assess the agreement between 2 methods of measurement that measure the same 
Table 1. Description of predictive equations

\begin{tabular}{ll}
\hline Equation name & Calculation of REE \\
\hline HB equation [13] & Men: $(66.5+(13.8 \times$ actBW $)+(5 \times \mathrm{Ht})-(6.8 \times$ age $)) \times 1.5$ \\
Women: $(655+(9.6 \times$ actBW $)+(1.8 \times \mathrm{Ht})-(4.7 \times$ age $) \times 1.5$ \\
\hline HB equation using an injury factor of & REE calculate by HB equation $\times 1.3$ \\
1.3 without an activity factor [12] & \\
\hline Mifflin equation [14] & Men: $5+(10 \times$ actBW $)+(6.25 \times$ Ht $)(5 \times$ age $)$ \\
\hline Mifflin equation with stress factor [15] & Women: $161+(10 \times$ actBW $)+(6.25 \times$ Ht $)-(5 \times$ age $)$ \\
\hline Ireton-Jones 1997 [17] & REE calculate by Mifflin equation $\times 1.25$ \\
\hline Penn state [18] & REE $=($ actBW $\times 5)-($ age $\times 11)+($ sex $\times 244)+($ trauma $\times 239)+($ burn $\times 840)+1,784$ \\
Modified Penn state [19] & is burn injury $(1)$ or not $(0)$ \\
\hline ACCP guidelines [20] & REE $=($ REE calculate by Mifflin $\times 0.96)+($ Tmax $\times 167)+($ VE $\times 31)(21)-6,212$ \\
\hline Faisy [9] & REE $=($ REE calculate by Mifflin $\times 0.71)+($ Tmax $\times 85)+($ VE $\times 64)-3,085$ \\
\hline
\end{tabular}

ActBW = Actual body weight (weight on admission in $\mathrm{kg}$ ); $\mathrm{Ht}=$ height $(\mathrm{cm})$; Tmax = maximum body temperature in the previous $24 \mathrm{~h}\left({ }^{\circ} \mathrm{C}\right) ; \mathrm{VE}=$ minute ventilation (liters per minute) at the time of measurement read from the ventilator.

Table 2. Demographic, clinical and nutritional characteristics of AKI patients

\begin{tabular}{lc}
\hline Characteristics & Values \\
\hline Age, years & $62.5 \pm 16.6$ \\
Male & $82(65.6)$ \\
ICU & $121(96.8)$ \\
AKI & $10(8)$ \\
$\quad$ Ischaemic & $2(1.6)$ \\
Mixed & $9(7.2)$ \\
Nephrotoxic & $104(83.2)$ \\
Associated with sepsis & $111(88.8)$ \\
Presence of sepsis & $28.5 \pm 4.73$ \\
APACHE II & $0.65 \pm 0.18$ \\
ATN-ISS & $28.2 \pm 7.9$ \\
BMI, kg/m ${ }^{2}$ & $6(4.8)$ \\
Underweight $(<18.5)$ & $40(32)$ \\
Normal $(18.5-24.9)$ & $37(29.6)$ \\
Overweight $(25-29.9)$ & $26(20.8)$ \\
Obese class $1(30-34.9)$ & $4(3.2)$ \\
Obese class 2 $(35.0-39.9)$ & $12(9.6)$ \\
Obese class 3 $(\geq 40)$ & $2,029 \pm 760$ \\
REE, kcal/day & $37.7 \pm 0.9$ \\
Maximum body temperature, ${ }^{\circ} \mathrm{C}$ & 73.6 \\
Mortality, \% & \\
\hline
\end{tabular}

Values are expressed as $\mathrm{n}(\%)$ and mean \pm SD.

ATN-ISS = Severity scoring individual in acute tubular necrosis. REE measured by IC. characteristic on the same scale [29]. The mean bias, which represents the difference between measured and calculated REE, is calculated by adding the differences between paired measurements and dividing the sum by the mean of paired measurements. A bias of zero represents a perfect agreement between methods (measured compared with calculated methods).

Two SDs were used to show the limits of agreement. To consider that the formula agrees with IC and assess clinical utility, in other studies [30-32], the limit of agreement was set as acceptable by $\pm 250 \mathrm{kcal}$ or $\pm 10 \%$ of the REE measured by IC. To analyze precision, if a majority $(>50 \%)$ of individual differences of REE was $>10 \%$ of the gold standard, the method was considered imprecise and clinically unacceptable. p values $<0.05$ were considered statistically significant. All analyses were performed using Medcalc for Windows version 12.2.1 (Mariakerke, Belgium).

\section{Results}

IC was performed in 125 severe AKI patients. The mean age was $62.5 \pm 16.6$ (range $18-94$ years) and $65.6 \%$ were male. The main etiology of AKI was associated with sepsis (83.2\%), and APACHE II and individual severity score of acute tubular necrosis were $28.5 \pm 4.73$ and $0.65 \pm 0.18$, respectively. Table 2 shows the demographic, clinical and nutritional characteristics of AKI patients. 
Table 3. Precision of REE measured and estimated by equation in AKI patients

\begin{tabular}{lcccc}
\hline & REE, kcal/day & Range, kcal/day & p value & Precision, \% \\
\hline IC & $2,029 \pm 760$ & $740-4,120$ & - & - \\
HB & $1,501 \pm 327$ & $995-2,685$ & $<0.001$ & 18 \\
HB IF & $1,951 \pm 426$ & $1,294-3,490$ & 0.275 & 36 \\
Mifflin & $1,659 \pm 292$ & $1,077-2,569$ & $<0.001$ & 29 \\
Mifflin SF & $2,074 \pm 365$ & $1,347-3,211$ & 0.345 & 25 \\
Ireton-Jones & $1,875 \pm 256$ & $1,306-2,559$ & 0.02 & 27 \\
Penn state & $1,947 \pm 341$ & $1,213-2,879$ & 0.519 & 33 \\
PSmod & $1,858 \pm 299$ & $1,244-2,728$ & 0.04 & 41 \\
ACCP & $1,916 \pm 554$ & $650-3,900$ & 0.151 & 25 \\
Faisy & $1,911 \pm 307$ & $1,081-2,681$ & 0.072 & 30 \\
\hline
\end{tabular}

Precision: number (\%) of subjects within $\pm 10 \%$ of REE measured by IC. state.

HB IF = HB using an injury factor; Mifflin SF = equation Mifflin with stress factor; PSmod = modified Penn

Table 4. Biases, limits of agreement, correlation coefficient and ICC between REE measured and prediction equations in AKI patients

\begin{tabular}{lllll}
\hline & Bias (95\% CI) & Limit of agreement & $\begin{array}{l}\text { Correlation } \\
\text { coefficient r (p value) }\end{array}$ & ICC (95\% CI) \\
\hline HB & $528(392$ to 663$)$ & -967.7 to $2,023.6$ & $0.21(0.02)$ & $0.15(-0.02$ to 0.32$)$ \\
HB IF & $77.6(-62.4$ to 217.6$)$ & $-1,472$ to $1,627.6$ & $0.21(0.02)$ & $0.18(0.001$ to 0.34$)$ \\
Mifflin & $370.1(232$ to 508.3$)$ & $-1,160$ to $1,900.3$ & $0.12(0.18)$ & $0.08(-0.09$ to 0.25$)$ \\
Mifflin SF & $-44.6(-186.7$ to 97.4$)$ & $-1,617.4$ to $1,528.2$ & $0.12(0.18)$ & $0.09(-0.08$ to 0.27$)$ \\
Ireton-Jones & $153.7(24.3$ to 283$)$ & $-1,278.7$ to 1,586 & $0.28(0.001)$ & $0.18(-0.004$ to 0.33$)$ \\
Penn State & $81.7(-49.7$ to 213.1$)$ & $-1,373$ to $1,536.5$ & $0.28(0.002)$ & $0.21(0.03$ to 0.37$)$ \\
PSmod & $170.8(43.5$ to 298.1$)$ & $-1,238.6$ to $1,580.1$ & $0.33(<0.001)$ & $0.23(0.06$ to 0.38$)$ \\
ACCP & $112.8(-41.6$ to 267.1$)$ & $-1,595.7$ to $1,821.2$ & $0.15(0.09)$ & $0.14(-0.03$ to 0.31$)$ \\
Faisy & $118.3(-10.8$ to 247.5$)$ & $-1,312.0$ to $1,548.7$ & $0.30(<0.001)$ & $0.21(0.03$ to 0.37$)$ \\
\hline
\end{tabular}

HB IF = HB using an injury factor; Mifflin SF = equation Mifflin with stress factor; PSmod = modified Penn state.

The BMI values $\left(11.6-57.5 \mathrm{~kg} / \mathrm{m}^{2}\right)$ covered all National Heart, Lung, and Blood Institute classifications, and the mean value of the populations fell in the overweight weight range (BMI $28.2 \pm 7.9 \mathrm{~kg} / \mathrm{m}^{2}$ ). Six percent of patients were underweight $\left(\mathrm{BMI}<18.5 \mathrm{~kg} / \mathrm{m}^{2}\right), 32 \%$ were normal-weight patients (BMI 18.5-24.9 kg/m²), 29.6\% were overweight, $20.8 \%$ were obese class $1,3.2 \%$ were obese class 2, and 9.6\% were obese class 3 .

Mean REE measured by IC was 2,029 $\pm 760 \mathrm{kcal} /$ day. The comparison between the REE assessed by IC and by the prediction equations is shown in table 3. The measured REE was significantly higher than the REE estimated by the equations HB, Mifflin, Ireton-Jones 1997 and modified Penn state. The precision was poor for all equa- tions. Modified Penn state equation had the best precision, although only $41 \%$ of cases had the predicted REE within $10 \%$ of their measured REE. Overall, the equations $\mathrm{HB}$ without using injury factor were the least precise, with only about $18 \%$ of cases having a predicted value within $10 \%$ of the measured REE. When using injury factor, this precision increased to $36 \%$.

As shown in table 4, the ICC for the nine equations was indicative of poor degree of reproducibility with IC. It can be noted that the ICC observed for the Penn state equation (0.23) was stronger than other, however, even with poor reproducibility.

Table 4 also summarizes the correlation coefficient, limits of agreement and bias of the equations with mea- 

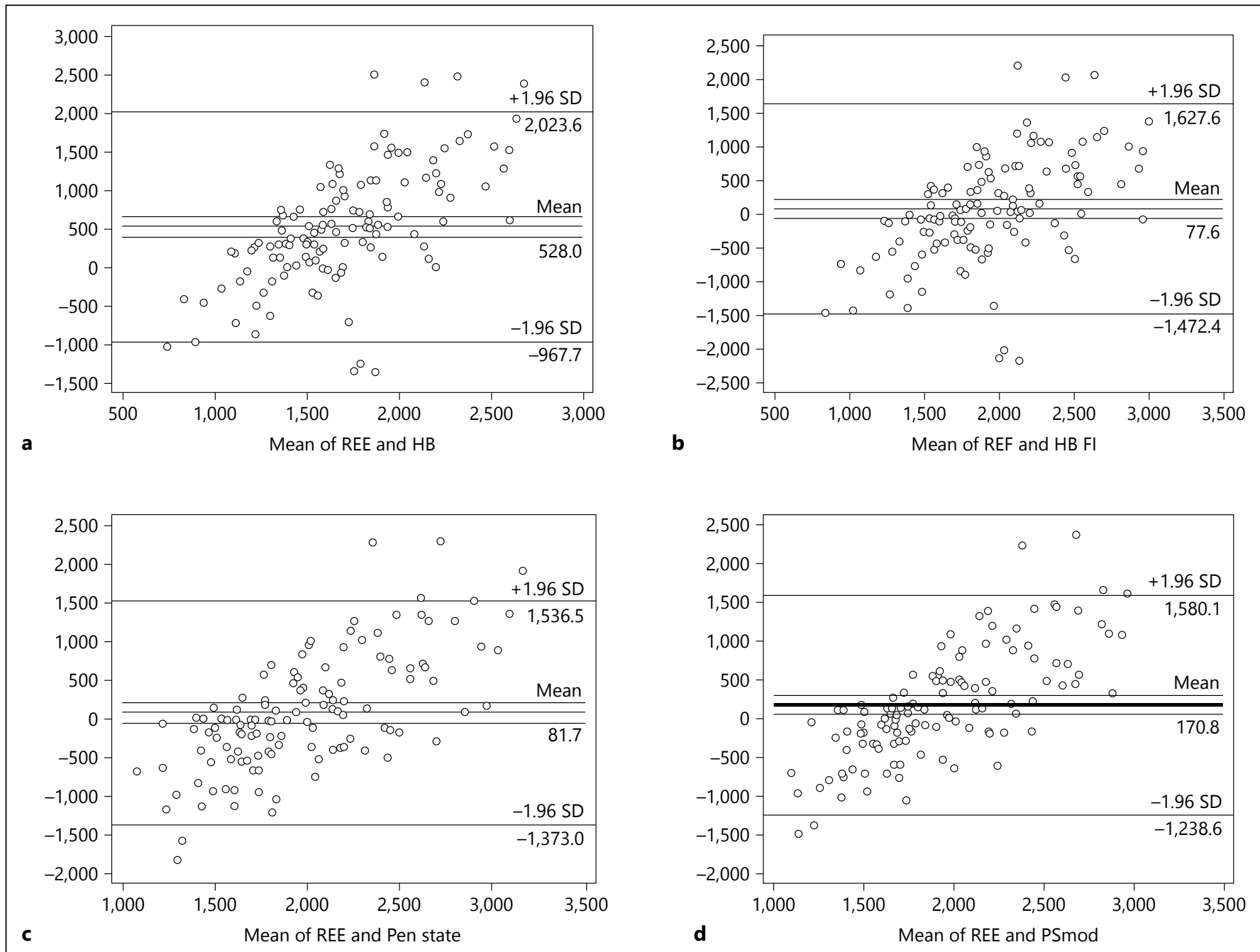

Fig. 1. Bland-Altman plots. Differences between REE measured and estimated using different prediction equations: a REE vs. HB equation; $\mathbf{b}$ REE vs. HB equation with injury factor; $\mathbf{c}$ REE vs. Penn state equation; $\mathbf{d}$ REE vs. modified Penn state equation. On the $y$ axis are plotted the values of the difference between the 2 methods

sure REE. The measured REE had significant correlation with $\mathrm{HB}$ equation with and without using an injury factor of 1.3, Ireton-Jones equation, Penn state equation, modified Penn state equation and Faisy equation; however, these correlations were weak $(\mathrm{r}<0.4)$.

The limits of agreement show the range of differences between the IC measurement and the REE predicted by the equations. For all equations, the limits of agreement range were large. For example, when evaluating patients using the $\mathrm{HB}$ equation, limits of agreement ranged from $-968 \mathrm{kcal} /$ day (IC less than predicted equation) to 2,024 $\mathrm{kcal} /$ day (IC higher than predicted equation). The large measured and estimated REE, and on the $\mathrm{x}$-axis, the values of average results by 2 methods. The limits of agreement were drawn (the average values of the differences $+1.96 \mathrm{SD}$ and the average differences - 1.96 SD). The middle line corresponds to the bias (the average of the differences between the methods) and its CI. wide limits of agreement in each case highlight the potential under or overfeeding of individual patients.

The individual agreement between IC and the prediction equations are shown in figures 1 and 2 using the Bland-Altman plot analysis. An association was found between the difference (y-axis) and the average ( $\mathrm{x}$-axis) for all equation ( $\mathrm{HB} \mathrm{r}=0.69$, $\mathrm{HB}$ using an injury factor $r=0.53$, Mifflin $r=0.75$, Mifflin with stress factor $r=0.63$, Ireton-Jones $r=0.81$, Penn state $r=0.68$, modified Penn state $r=0.75$, ACCP guidelines $r=0.31$, Faisy $r=0.74$; all $\mathrm{p}<0.001)$. This revealed a trend-bias for equations; that is, by increasing average, the difference rises. 

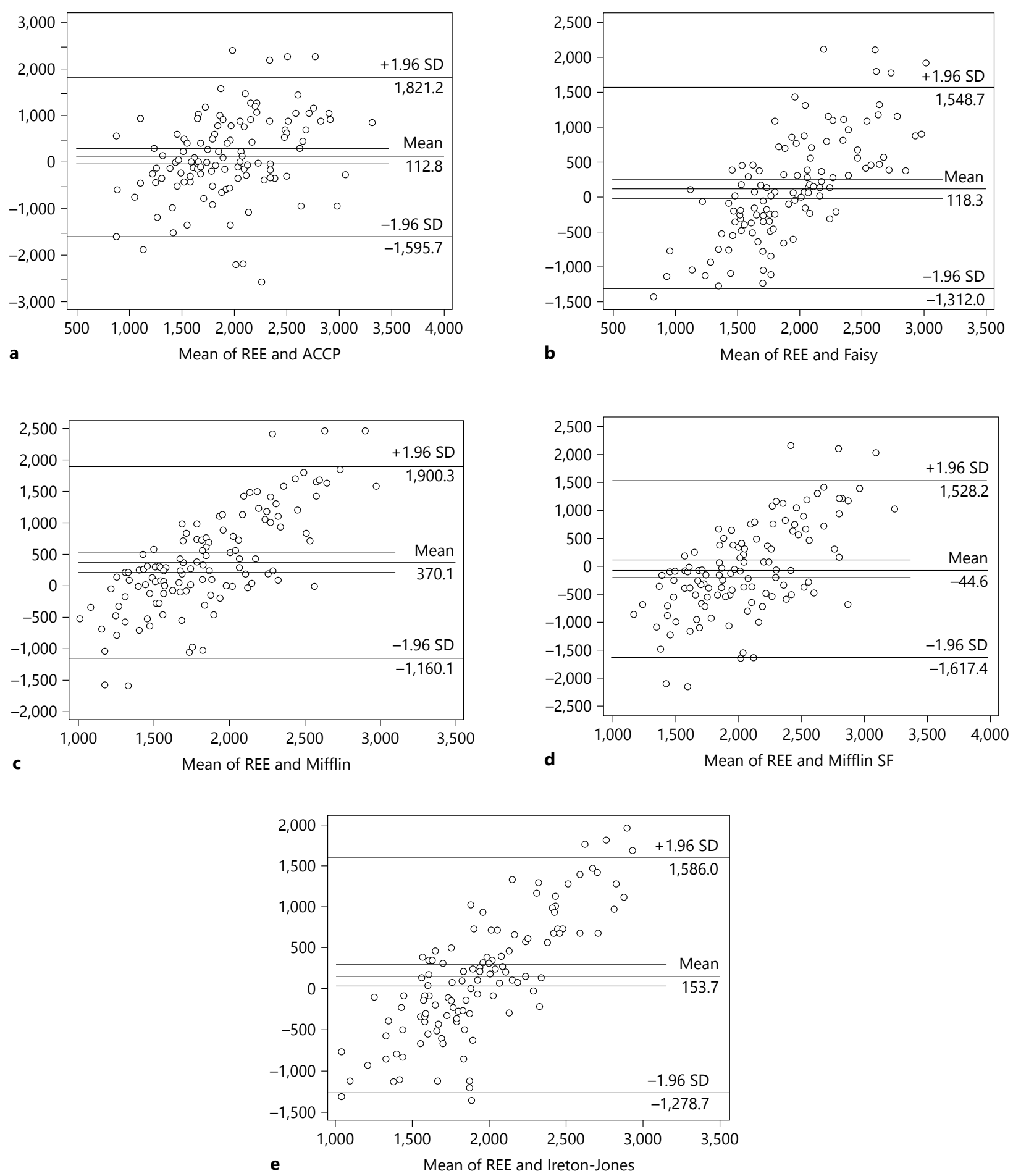

Fig. 2. Bland-Altman plots. Differences between REE measured and estimated using different prediction equations: a REE vs. ACCP guidelines; b REE vs. Faisy equation; c REE vs. Mifflin equation; d REE vs. Mifflin equation with stress factor; e REE vs. IretonJones equation. On the $y$-axis are plotted the values of the difference between the 2 methods measured and estimated REE, and on the $\mathrm{x}$-axis, the values of average results by 2 methods. The limits of agreement were drawn (the average values of the differences +1.96 $\mathrm{SD}$ and the average differences $-1.96 \mathrm{SD}$ ). The middle line corresponds to the bias (the average of the differences between the methods) and its CI. 


\section{Discussion}

Using this data set, we have demonstrated that none of the equations used to predict REE agree well with actual energy expenditure measured by IC in severe AKI patients.

It may be argued that inaccurate predictions are expected when equations developed long ago (e.g. the $\mathrm{HB}$ ) or based on data from healthy volunteers (e.g. HB and Mifflin-St Jeor) are applied to ill hospitalized patients. The HB equation represents REE as developed from 239 mostly normal weight, white men and women evaluated in the first 2 decades of the 20th century [17]. The poor resemblance of those healthy samples to hospitalized patients seen currently includes a greater diversity in body composition, obesity, and race.

In our study, HB equation was the least precise, with poor reproducibility (ICC 0.15 ). Only about $18 \%$ of cases had a predicted value within $10 \%$ of the measured REE. In general, the equation underestimated REE in approximately $500 \mathrm{kcal} /$ day. The limits of agreement between the equation and measured REE were large (-967.7 to 2,023.6 kcal/ day), showing the low agreement between the methods.

In a systematic review, Frankenfield et al. [14] reported the results of an evidence analysis of the accuracy of metabolic rate calculation methods. HB equation presented mean differences between the resting metabolic rate measured and predicted; these differences ranged from 250 to $900 \mathrm{kcal} /$ day (some individual differences may be much higher). As in our study, this equation underestimated the resting metabolic rate in critically ill patients. That work group concluded that the unmodified HB equation was not sufficiently accurate for clinical use in critically ill patients and this conclusion carries a grade of I (i.e. good evidence) [14].

Due to the inaccuracy of this equation, the correction factors were studied. Normally, the values calculated using $\mathrm{HB}$ equation are multiplied by correction factors to adjust energy expenditure to the current individual situation, adapting the energy expenditure to the current individual situation. There are a wide range of multiplication factors used in the published studies (injury factor, stress factor, activity factor; thermal factor, among others) [14-16]. In our study, we used HB equation $\times 1.3$ (injury factor) and we did not use an activity factor, in an attempt to reduce the error in equation (underestimate) in AKI patients in dialysis.

In our study, using the injury factor, the $\mathrm{HB}$ equation had higher precision than without injury factor (36\%) and the mean difference between measured and estimat- ed REE (bias) was lower (77.6 kcal/day) showing reduction in probability to underestimate the REE. However, this equation remained with poor degree of reproducibility (ICC 0.18), and poor agreement with IC (limits of agreement large, range $-1,472$ to $1,627.6 \mathrm{kcal} /$ day). Other studies also showed low concordance and accuracy between the equation $\mathrm{HB}$ and IC, even using the injury factor $[6,13,16,33-36]$.

Review studies have suggested not to use the HB equation, with or without correction factors, in critically AKI patients because it underestimated and/or overestimated REE and was inaccurate and unreliable for ICU patients $[14,37]$.

Similar to HB equation, the Mifflin-St Jeor equation [18] is a regression equation that combines weight, height, age, and gender to predict resting metabolic rate in healthy people. According to the published evidence, an ADA work group determined that the Mifflin-St Jeor equation was the most accurate method to predict the resting metabolic rate in healthy obese and no obese people. The use of Mifflin-St Jeor equation in critical care has been little studied [14]. We found poor agreement between REE estimated by Mifflin-St Jeor equation using or not using stress factor and measured REE by IC (limits of agreement $-1,617$ to 1,528 and $-1,160$ to $1,900 \mathrm{kcal} /$ day, respectively). This equation had the lower $\operatorname{ICC}(0.08,0.09)$ and precision $(25,29 \%)$ and tended to underestimate the REE when the stress factor is not used or overestimate when it is added.

In literature, Mifflin equation had poor agreement and underestimated REE in critically ill patients, in all BMI groups, and may underestimate further than the $\mathrm{HB}$ equation $[6,14,38,39]$.

Unlike previous equations, the Ireton-Jones, Penn state and Faisy equation were developed from REE measurements of hospitalized and critically ill patients, and dynamic variables as body temperature and minute ventilation that reflect the metabolic state of the patient were added.

Although they are intended for use in critical patients, in our population of AKI patients, all these formulas had poor agreement with measured REE by IC.

Frankenfield et al. [15] compared energy expenditure equations to measurements by IC in 202 mechanically ventilated critically ill patients divided into $<60$ or $>60$ years and BMI $<30$ or $>30 \mathrm{~kg} / \mathrm{m}^{2}$. Seventeen equations were evaluated and the Penn state equation was the most accurate (precision 67\%).

Kross et al. [6] evaluated the energy expenditure equations in a total of 927 patients, including 401 obese pa- 
tients. They found there was poor agreement between REE measured by IC and REE predicted by the HB, ACCP, Mifflin, and the Ireton-Jones equations. In all cases, except using Ireton-Jones, the predictive equations underestimated measured REE.

Review studies also suggest that Ireton-Jones, Penn state, Faisy and ACCP equation has no sufficient accuracy and agreement with measured REE in critically ill patients and should not replace the use of IC $[14,30,40$, $41]$.

In our study, these equations underestimated the REE measured by IC (Ireton-Jones $154 \mathrm{kcal} /$ day less than measured REE, Penn state $82 \mathrm{kcal} /$ day; Penn state modified $171 \mathrm{kcal} /$ day; Faisy $118 \mathrm{kcal} /$ day and ACCP $113 \mathrm{kcal} /$ day). Although, Penn state modified equation has presented a higher precision (41\%) and ICC (0.23), it is not enough as an indication of use in critically ill AKI patients. Using universal prediction equations to critical ill AKI patients, errors of prediction can occur and lead to overfeeding or underfeeding if they are used to guide the feeding regimen of these patients [14].

The reason why these equations are not accurate in these patients is not clear. The kidneys are responsible for many regulatory functions, such as acid-base balance, fluid and electrolyte balance, gluconeogenesis, the secretion of erythropoietin and conversion of vitamin D3 to its active form. While the kidneys are responsible for only $10 \%$ of energy expenditure, metabolic disorders, and proinflammatory state associated with renal failure, the underlying disease process and comorbidities could alter energy expenditure [12]. However, energy expenditure is not apparently increased by AKI. There is only one study on AKI population, and it showed that the REE was around $130 \%$ of normal, calculated by the $\mathrm{HB}$ equation, in patients with sepsis and AKI [42].

Some limitations should be recognized. First, the use of weight on admission can overestimate the actual weight due to pre-ICU procedures (such as resuscitation). However, as we are evaluating patients with severe AKI, the current weight probably offer a greater error due to edema. Moreover, in some cases, the patient's weight at admission was not available, and therefore, the weight information collected from patients' caretakers was used instead. The same was done with height and can lead to an incorrect estimate of REE.

Second, we were not able to examine all the predictive equations currently used in practice because we were unable to obtain some pieces of clinical information needed to perform them. For example, we were unable to calculate the Swinamer equation, commonly used to predict the energy needs for ventilated patients because we could not obtain information on tidal volume. However, the equations that we evaluated contain clinical information readily available to practitioners, making them clinically useful equations for critical care clinicians to use. Third, we did not have information about treatments that might influence energy expenditure and carbon dioxide production, including type of nutrition and energy intake, catecholamine, neuromuscular blocking agents, and opioids.

Another limitation is that we only have REE measure at one moment. Day-to-day variations in energy expenditure of between 4 and 56\% have been reported [43]. Because of this variability in REE, one measurement, which is then extrapolated to represent several days may introduce significant error. Thus, REE measured is representative of that moment, and the same for REE estimated in the equations. For the monitoring of patients, further measures REE must be made of both the IC, as the equations.

Finally, because we studied a select population of patients, those with severe AKI, our findings may not be generalizable to all AKI, or critically ill patients and, finally, only 1 IC measurement was performed, whereas repeated measurements are recommended to cope with the dynamic alterations of energy metabolism during the course of critical illness.

Despite limitations, this is the largest study to reports that predictive equations do not accurately estimate REE in critically ill AKI patients. None of the prediction equations evaluated in this study had accuracy higher than $50 \%$, and may result in such a high value as $80 \%$ of patients receiving inadequate or excessive energy intakes. Our findings support the need to conduct a controlled prospective study to develop an appropriate prediction equation to assess energy needs for critically ill AKI patients. Alternatively, because of the limitations of the predictive formula, IC may be required to assess the energy needs in severe AKI patients requiring dialysis.

\section{Acknowledgments}

This study was supported by grant number 2013/00315-1, São Paulo Research Foundation (FAPESP). Ms. C.R. de Góes was responsible for the data collection, interpretation of the results and writing of the manuscript. A.C.S. Sanches and P.S. Xavier contributed to the collection for the data. D. Ponce, PhD, A.L. Balbi and M.N. Berbel-Bufarah contributed to the conception and design of the study and to the writing of the manuscript. There are no conflicts of interest to disclose. 


\section{References}

1 Ávila MO, Rocha PN, Zanetta DM, Yu L, Burdmann Ede A: Water balance, acute kidney injury and mortality of intensive care unit patients. J Bras Nefrol 2014;36:379-388.

2 Fiaccadori E, Lombardi M, Leonardi S, Rotelli CF, Tortorella G, Borghetti A: Prevalence and clinical outcome associated with preexisting malnutrition in acute renal failure: a prospective cohort study. J Am Soc Nephrol 1999; 10:581-593.

3 Guimarães SM, Lima EQ, Cipullo JP, Lobo SM, Burdmann EA: Low insulin-like growth factor-1 and hypocholesterolemia as mortality predictors in acute kidney injury in the intensive care unit. Crit Care Med 2008;36: 3165-3170.

4 Alberda C, Gramlich L, Jones N, Jeejeebhoy K, Day AG, Dhaliwal R, et al: The relationship between nutritional intake and clinical outcomes in critically ill patients: results of an international multicenter observational study. Intensive Care Med 2009;35:1728-1737.

5 Wei X, Day AG, Ouellette-Kuntz H, Heyland DK: The association between nutritional adequacy and long-term outcomes in critically ill patients requiring prolonged mechanical ventilation: a multicenter cohort study. Crit Care Med 2015;43:1569-1579.

6 Kross EK, Sena M, Schmidt K, Stapleton RD: A comparison of predictive equations of energy expenditure and measured energy expenditure in critically ill patients. J Crit Care 2012;27:321.e5-e12.

7 Kan MN, Chang $\mathrm{HH}$, Sheu WF, Cheng $\mathrm{CH}$, Lee BJ, Huang YC: Estimation of energy requirements for mechanically ventilated, critically ill patients using nutritional status. Crit Care 2003;7:R108-R115.

8 Rubinson L, Diette GB, Song X, Brower RG, Krishnan JA: Low caloric intake is associated with nosocomial bloodstream infections in patients in the medical intensive care unit. Crit Care Med 2004;32:350-357.

9 Tappy L: Metabolic consequences of overfeeding in humans. Curr Opin Clin Nutr Metab Care 2004;7:623-628.

10 Vo NM, Waycaster M, Acuff RV, Lefemine AA: Effects of postoperative carbohydrate overfeeding. Am Surg 1987;53:632-635.

11 Klein CJ, Stanek GS, Wiles CE 3rd: Overfeeding macronutrients to critically ill adults: metabolic complications. J Am Diet Assoc 1998; 98:795-806.

12 McCarthy MS, Phipps SC: Special nutrition challenges: current approach to acute kidney injury. Nutr Clin Pract 2014;29:56-62.

13 Faisy C, Guerot E, Diehl JL, Labrousse J, Fagon JY: Assessment of resting energy expenditure in mechanically ventilated patients. Am J Clin Nutr 2003;78:241-249.

14 Frankenfield D, Hise M, Malone A, Russell M, Gradwell E, Compher C: Prediction of resting metabolic rate in critically ill adult patients: results of a systematic review of the evidence. J Am Diet Assoc 2007;107:1552-1561.
15 Frankenfield DC, Coleman A, Alam S, Cooney RN: Analysis of estimation methods for resting metabolic rate in critically ill adults. JPEN J Parenter Enteral Nutr 2009;33: 27-36.

16 MacDonald A, Hildebrandt L: Comparison of formulaic equations to determine energy expenditure in the critically ill patient. Nutrition 2003; 19:233-239.

17 Harris JA, Benedict FG: A biometric study of human basal metabolism. Proc Natl Acad Sci U S A 1918;4:370-373.

18 Mifflin MD, St Jeor ST, Hill LA, Scott BJ, Daugherty SA, Koh YO: A new predictive equation for resting energy expenditure in healthy individuals. Am J Clin Nutr 1990;51: 241-247.

19 Schlein KM, Coulter SP: Best practices for determining resting energy expenditure in critically ill adults. Nutr Clin Pract 2014;29:44-55.

20 Ireton-Jones CS, Turner WW Jr, Liepa GU, Baxter CR: Equations for the estimation of energy expenditures in patients with burns with special reference to ventilatory status. J Burn Care Rehabil 1992;13:330-333.

21 Ireton-Jones CS, Jones JD: Why use predictive equations for energy expenditure assessment? J Am Diet Assoc 1997;97(suppl):A44.

22 Frankenfield D, Smith JS, Cooney RN: Validation of 2 approaches to predicting resting metabolic rate in critically ill patients. JPEN J Parenter Enteral Nutr 2004;28:259-264.

23 Frankenfield D: Validation of an equation for resting metabolic rate in older obese, critically ill patients. JPEN J Parenter Enteral Nutr 2011;35:264-269.

24 Cerra FB, Benitez MR, Blackburn GL, Irwin RS, Jeejeebhoy K, Katz DP, et al: Applied nutrition in ICU patients. A consensus statement of the American College of Chest Physicians. Chest 1997;111:769-778.

25 Vilar E, Machado A, Garrett A, Kozarski R, Wellsted D, Farrington K: Disease-specific predictive formulas for energy expenditure in the dialysis population. J Ren Nutr 2014;24: 243-251.

26 Mehta RL, Kellum JA, Shah SV, Molitoris BA, Ronco C, Warnock DG, et al: Acute kidney injury network: report of an initiative to improve outcomes in acute kidney injury. Crit Care 2007;11:R31.

27 Weir JB: New methods for calculating metabolic rate with special reference to protein metabolism. J Physiol 1949;109:1-9.

28 Lee J, Koh D, Ong CN: Statistical evaluation of agreement between two methods for measuring a quantitative variable. Comput Biol Med 1989;19:61-70.

29 Bland JM, Altman DG: Statistical methods for assessing agreement between two methods of clinical measurement. Lancet 1986;1:307310 .
30 Boullata J, Williams J, Cottrell F, Hudson L, Compher C: Accurate determination of energy needs in hospitalized patients. J Am Diet Assoc 2007; 107:393-401.

31 Reid CL: Poor agreement between continuous measurements of energy expenditure and routinely used prediction equations in intensive care unit patients. Clin Nutr 2007;26: 649-657

32 Robins K, Stankorb SM, Salgueiro M: Energy expenditure in acute posttraumatic amputation: comparison of four methods for assessment. Nutr Clin Pract 2013;28:758-765.

33 Casati A, Colombo S, Leggieri C, Muttini S, Capocasa T, Gallioli G: Measured versus calculated energy expenditure in pressure support ventilated ICU patients. Minerva Anestesiol 1996;62:165-170.

34 O'Leary-Kelley CM, Puntillo KA, Barr J, Stotts N, Douglas MK: Nutritional adequacy in patients receiving mechanical ventilation who are fed enterally. Am J Crit Care 2005; 14: 222-231.

35 Hickmann CE, Roeseler J, Castanares-Zapatero D, Herrera EI, Mongodin A, Laterre PF: Energy expenditure in the critically ill performing early physical therapy. Intensive Care Med 2014;40:548-555.

36 De Waele E, Spapen H, Honoré PM, Mattens S, Van Gorp V, Diltoer M, et al: Introducing a new generation indirect calorimeter for estimating energy requirements in adult intensive care unit patients: feasibility, practical considerations, and comparison with a mathematical equation. J Crit Care 2013;28:884.e1-e6.

37 Walker RN, Heuberger RA: Predictive equations for energy needs for the critically ill. Respir Care 2009;54:509-521.

38 Frankenfield DC, Ashcraft CM, Galvan DA: Prediction of resting metabolic rate in critically ill patients at the extremes of body mass index. JPEN J Parenter Enteral Nutr 2013;37: 361-367.

39 Anderegg BA, Worrall C, Barbour E, Simpson $\mathrm{KN}$, Delegge M: Comparison of resting energy expenditure prediction methods with measured resting energy expenditure in obese, hospitalized adults. JPEN J Parenter Enteral Nutr 2009;33:168-175.

40 Cooney RN, Frankenfield DC: Determining energy needs in critically ill patients: equations or indirect calorimeters. Curr Opin Crit Care 2012;18:174-177.

41 Spapen H, De Waele E, Diltoer M, Gorp V, Honoré P, Mattens S: Calculating energy needs in critically ill patients: sense or nonsense? J Transl Intern Med 2014;2:150.

42 Schneeweiss B, Graninger W, Stockenhuber F, Druml W, Ferenci P, Eichinger S, et al: Energy metabolism in acute and chronic renal failure. Am J Clin Nutr 1990;52:596-601.

43 Weissman C, Kemper M, Hyman AI: Variation in the resting metabolic rate of mechanically ventilated critically ill patients. Anesth Analg 1989;68:457-461. 